\title{
Efficiency of applying ammonium oxalate for protection of monumental limestone by poultice, immersion and brushing methods
}

ARTICLE in APPLIED PHYSICS A · APRIL 2012

Impact Factor: $1.7 \cdot$ DOI: $10.1007 /$ s00339-012-7365-9

CITATIONS

5

8 AUTHORS, INCLUDING:

Frederik Vanmeert

University of Antwerp

34 PUBLICATIONS 173 CITATIONS

SEE PROFILE

\section{Koen Janssens}

University of Antwerp

387 PUBLICATIONS 5,369 CITATIONS

SEE PROFILE
READS

95

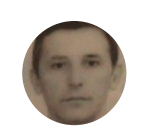

S. Fazinic

Ruđer Bošković Institute

86 PUBLICATIONS 641 CITATIONS

SEE PROFILE

Darko Tibljas

University of Zagreb

36 PUBLICATIONS 222 CITATIONS

SEE PROFILE 


\title{
Efficiency of applying ammonium oxalate for protection of monumental limestone by poultice, immersion and brushing methods
}

\author{
D. Mudronja $\cdot$ F. Vanmeert $\cdot$ K. Hellemans $\cdot$ S. Fazinic $\cdot$ \\ K. Janssens $\cdot$ D. Tibljas $\cdot$ M. Rogosic $\cdot$ S. Jakovljevic
}

Received: 5 June 2012 / Accepted: 16 October 2012 / Published online: 30 October 2012

(c) Springer-Verlag Berlin Heidelberg 2012

\begin{abstract}
Samples of cretaceous limestone have been treated with three application methods (poultice, immersion and brushing) using different concentrations of ammonium oxalate solution $(\mathrm{AmOx})$ and varying treatment time in order to test the efficiency of surface and in-depth formation of a protective layer of calcium oxalate $(\mathrm{CaOx})$. Synchrotron-based microanalytical techniques (SR- $\mu$ XRD with $12.5 \mu \mathrm{m} \times 7.5 \mu \mathrm{m}(H \times V)$ probe size, SR- $\mu$ FTIR with $10 \mu \mathrm{m} \times 10 \mu \mathrm{m}$ and $8 \mu \mathrm{m} \times 20 \mu \mathrm{m}$ probe sizes) and laboratory $\mu$ FTIR, XRD and SEM have been employed for analysis of the treated samples. Synchrotron-based techniques showed variations in the $\mathrm{CaOx}$ distribution along the surface on a micrometer scale. All treatments resulted in the
\end{abstract}

D. Mudronja $(\varangle)$

Natural Science Laboratory, Croatian Conservation Institute, Grskoviceva 23, 10000 Zagreb, Croatia

e-mail: dmudronja@h-r-z.hr

F. Vanmeert $\cdot$ K. Hellemans $\cdot$ K. Janssens

Department of Chemistry, University of Antwerp,

Groenenborgerlaan 171, 2610 Antwerp, Belgium

\section{S. Fazinic}

Laboratory for Ion Beam Interactions, Rudjer Boskovic Institute, Bijenicka c. 54, 10000 Zagreb, Croatia

\section{Tibljas}

Institute of Mineralogy and Petrology, Department of Geology, Faculty of Science, University of Zagreb, Horvatovac 95, 10000 Zagreb, Croatia

\section{Rogosic}

Faculty of Chemical Engineering and Technology,

University of Zagreb, Marulicev trg 19, 10000 Zagreb, Croatia

\section{S. Jakovljevic}

Faculty of Mechanical Engineering and Naval Architecture,

University of Zagreb, I. Lucica 5, 10000 Zagreb, Croatia development of a $\mathrm{CaOx}$ layer with a maximum thickness of approximately $40 \mu \mathrm{m}$. Application by the brushing method with 10 1-min applications with 5-min breaks during one hour showed a development of the calcium oxalate layer equivalent to the poultice treatment taking $10 \mathrm{~h}$. This treatment could be preferred for large marble or limestone surfaces where poultice usage is economically not feasible.

\section{Introduction}

Natural calcium oxalate patinas on marble and limestone monuments have long been noted for their apparently protective properties in a range of environments [1-3]. Wellknown examples include the Parthenon in Athens [4] and Trajan's Column in Rome [5]. The idea of producing artificial calcium oxalate $(\mathrm{CaOx})$, in a reaction with ammonium oxalate (AmOx), as a conversion coating to provide an acidresistant and compatible treatment for weak stone and plaster originated in the mid 1980s and continued through the 1990s [6-12]. The protective action of both natural and artificially created $\mathrm{CaOx}$ is due to the fact that, at a $\mathrm{pH}<7$, it has significantly lower solubility than calcium carbonate $[6,13]$. To create a $\mathrm{CaOx}$ protective layer, the main method for application of AmOx utilized by Opificio delle Pietre Dure (OPD) [6] in Florence is using a saturated AmOx solution $(5 \%)$ applied with a cellulose poultice to the stone surface for a period of 24 to $36 \mathrm{~h}$.

In this paper other possible AmOx application methods, using different concentrations of AmOx and treatment times, have been compared to the poultice application method. The poultice method is economically feasible only for smaller stone objects but not for large surfaces like buildings. Therefore, an alternative brushing application treatment has been investigated. Also, the efficiency of the immersion method, which could be applicable to smaller 
objects, has been compared to the poultice and brushing methods.

\section{Experimental}

\subsection{Materials}

Cretaceous limestone commercially called Veselje, from the island of Brac in Croatia, has been selected for this study. This is a very important building stone in Croatia even from the ancient times. Many monuments from the Roman period in this region were built with this type of stone. For instance, it was used for building many parts of Diocletian's palace in Split, a UNESCO World Heritage Site [14] on which conservation work is in progress. Veselje is a light-grey stone mainly composed of rudist shell clasts and has a porosity of $6.2 \%$. Petrologically it is determined as bioclastic packestone/wackestone to bioclastic floatstone.

AmOx solutions ( 2 and $5 \%$ ) were created from ammonium oxalate monohydrate $99.5 \%\left(\mathrm{C}_{2} \mathrm{H}_{8} \mathrm{~N}_{2} \mathrm{O}_{4} \cdot \mathrm{H}_{2} \mathrm{O}\right)$ CAS No. 6009-70-7 (Acros Organics). A mixture of $2 / 3$ arbocel 1000 and $1 / 3$ arbocel 200 has been used as poultice.

\subsection{Sample preparation}

Veselje stone was cut to $5 \mathrm{~cm} \times 5 \mathrm{~cm} \times 3 \mathrm{~cm}$ parallelepipeds. Prepared samples were not polished with the aim to better simulate the actual situation in conservation practice.

After AmOx treatment, samples to be analyzed with synchrotron-based (SR) micro X-ray diffraction ( $\mu \mathrm{XRD}$ ) were cut in half to $5 \mathrm{~cm} \times 2.5 \mathrm{~cm} \times 3 \mathrm{~cm}$ to allow crosssectional measurement of the calcium oxalate layer. For SR micro Fourier transform infrared $(\mu \mathrm{FTIR})$ and scanning electron microscopy (SEM) investigations, $5 \mathrm{~mm} \times 5 \mathrm{~mm} \times$ $5 \mathrm{~mm}$ cubes were cut out from the treated parallelepipeds.

AmOx was applied by brushing, immersion or poultice methods. For the brushing method, 2 or $5 \%$ AmOx was applied to the stone surface by 10 brushing intervals over a period of one hour. Each brushing interval lasted one minute followed by a five-minute break. Stone parallelepipeds were positioned horizontally during brushing, while during break time and after the procedure they were in vertical position. For the immersion method, samples have been immersed in a 2 or $5 \%$ solution of AmOx to a depth of $3 \mathrm{~mm}$ for 1 , 5,10 and $24 \mathrm{~h}$, respectively. For the poultice method, a 2 or $5 \%$ solution of AmOx has been applied in a cellulose poultice over a Japanese paper sheet for 1, 5, 10 and $24 \mathrm{~h}$, respectively.

During poultice treatment, stone parallelepipeds were positioned horizontally. To test how stirring during the immersion procedure affects the $\mathrm{CaOx}$ formation, Veselje stone has been ground to $0.125-0.250 \mathrm{~mm}$ particles and treated by immersion in 2 and $5 \%$ solutions of AmOx with and without stirring for one hour.

Treatment methods used for the different samples are described in Table 1.

\subsection{Analytical techniques}

The surface of all samples was investigated by XRD, $\mu$ FTIR spectroscopy and SEM. The surface of some samples (Table 1) was studied using synchrotron-based $\mu$ FTIR spectroscopy (SR- $\mu$ FTIR). To obtain the thickness of the calcium oxalate layers formed, depth profiles were measured by SR$\mu$ XRD.

The surface morphology of all samples has been analyzed by SEM using a Tescan VEGA instrument with BSE detector at $20 \mathrm{kV}$.

For XRD continuous scans $\left(0.02^{\circ} \theta / \mathrm{s}\right)$, a Philips vertical goniometer (type $\mathrm{X}^{\prime}$ Pert) equipped with a $\mathrm{Cu}$ tube $(45 \mathrm{kV}$, $40 \mathrm{~mA}$ ) with a proportional counter was used. A quasiparallel beam was obtained by a graded multilayer parabolic $\mathrm{X}$-ray mirror. Slits on the instrument were as follows: mask $10 \mathrm{~mm}$, divergency slit $1 / 4^{\circ}$, anti-scatter slit $1 / 2^{\circ}$ on tube side and $1^{\circ}$ before the counter and receiving slit $0.2 \mathrm{~mm}$. In the XRD chamber samples were positioned with a microscope table and two laser diodes. Examined surface areas were approximately $1 \mathrm{~cm}^{2}$ in size. Mineral phases were determined with X'Pert HighScore Plus software [15] using the PDF-2 database [16].

$\mu$ FTIR spectroscopy was performed using a laboratory instrument (Thermo-Nicolet iN10 MX) with $50 \mu \mathrm{m} \times 50 \mu \mathrm{m}$ IR window by the fast-mapping option, scanning surfaces of a few square $\mathrm{mm}$.

SR- $\mu$ FTIR spectroscopy was performed at the SMIS beamline (SOLEIL synchrotron) and at the IR beamline ('Swiss Light Source (SLS)' synchrotron). At the SMIS beamline $\mathrm{CaOx}$ distribution surface maps were measured using a Thermo-Nicolet Continuum IR microscope with the $10 \mu \mathrm{m} \times 10 \mu \mathrm{m}$ collimated IR beam from the synchrotron. Surface areas of $400 \mu \mathrm{m} \times 400 \mu \mathrm{m}$ were scanned, except for sample A5, where four $50 \mu \mathrm{m} \times 50 \mu \mathrm{m}$ maps were measured and on sample B2/5, where a $350 \mu \mathrm{m} \times 350 \mu \mathrm{m}$ map was measured. At the IR beamline of SLS, surface maps on the same samples were measured with a Bruker Hyperion 3000 IR microscope with a $(8 \mu \mathrm{m} \times 20 \mu \mathrm{m})$ collimated IR beam. Measured $\mu$ FTIR and SR- $\mu$ FTIR surface maps were analyzed with CytoSpec, a program designed specifically for the statistical analysis of vibrational spectroscopic imaging data sets [17]. The software was used to perform cluster analysis of the acquired spectra. Dendrograms were produced, clustering similar spectra together and producing related average spectra, which could be correlated with the various chemical phases present. Colored maps indicating the location of the phases were produced, representing the surface of the analyzed samples. 
Table 1 List of the samples with a description of the treatment method applied for the formation of the calcium oxalate layer (for details see text) and the techniques used for analysis

\begin{tabular}{|c|c|c|}
\hline Sample code & Treatment method & Analytical technique \\
\hline A2 & Brushing with $2 \% \mathrm{AmOx}$ & $1,2,3,5$ \\
\hline A5 & Brushing with $5 \%$ AmOx & $1,2,3,4,5$ \\
\hline B2/1 & Immersion in $2 \% \mathrm{AmOx}$ for $1 \mathrm{~h}$ & $1,2,3,5$ \\
\hline $\mathrm{B} 2 / 5$ & Immersion in $2 \% \mathrm{AmOx}$ for $5 \mathrm{~h}$ & $1,2,3,4,5$ \\
\hline $\mathrm{B} 2 / 10$ & Immersion in $2 \% \mathrm{AmOx}$ for $10 \mathrm{~h}$ & $1,2,4,5$ \\
\hline $\mathrm{B} 2 / 24$ & Immersion in $2 \% \mathrm{AmOx}$ for $24 \mathrm{~h}$ & $1,2,3,4,5$ \\
\hline B5/1 & Immersion in $5 \% \mathrm{AmOx}$ for $1 \mathrm{~h}$ & $1,2,3,5$ \\
\hline $\mathrm{B} 5 / 5$ & Immersion in $5 \% \mathrm{AmOx}$ for $5 \mathrm{~h}$ & $1,2,3,4,5$ \\
\hline $\mathrm{B} 5 / 10$ & Immersion in $5 \% \mathrm{AmOx}$ for $10 \mathrm{~h}$ & $1,2,3,4,5$ \\
\hline $\mathrm{B} 5 / 24$ & Immersion in $5 \% \mathrm{AmOx}$ for $24 \mathrm{~h}$ & $1,2,3,4,5$ \\
\hline $\mathrm{C} 2 / 1$ & Poultice-2 \% AmOx for $1 \mathrm{~h}$ & $1,2,3,5$ \\
\hline $\mathrm{C} 2 / 5$ & Poultice-2 $\%$ AmOx for $5 \mathrm{~h}$ & $1,2,3,4,5$ \\
\hline $\mathrm{C} 2 / 10$ & Poultice-2\% AmOx for $10 \mathrm{~h}$ & $1,2,3,5$ \\
\hline $\mathrm{C} 2 / 24$ & Poultice-2 \% AmOx for $24 \mathrm{~h}$ & $1,2,3,4,5$ \\
\hline $\mathrm{C} 5 / 1$ & Poultice-5 $\%$ AmOx for $1 \mathrm{~h}$ & $1,2,3,5$ \\
\hline $\mathrm{C} 5 / 5$ & Poultice-5 \% AmOx for $5 \mathrm{~h}$ & $1,2,3,4,5$ \\
\hline $\mathrm{C} 5 / 10$ & Poultice-5\% AmOx for $10 \mathrm{~h}$ & $1,2,3,5$ \\
\hline $\mathrm{C} 5 / 24$ & Poultice-5\% AmOx for $24 \mathrm{~h}$ & $1,2,3,4,5$ \\
\hline B5/1 nomix & Immersion of ground stone $(0.125-0.250 \mathrm{~mm})$ in $5 \% \mathrm{AmOx}$ for $1 \mathrm{~h}$ & 2,6 \\
\hline $\mathrm{B} 5 / 1 \mathrm{mix}$ & Immersion with stirring of ground stone $(0.125-0.250 \mathrm{~mm})$ in $5 \%$ AmOx for $1 \mathrm{~h}$ & 2,6 \\
\hline
\end{tabular}

${ }^{\mathrm{a}} 1=\mathrm{SEM}, 2=\mathrm{XRD}, 3=\mathrm{SR}-\mu \mathrm{XRD}-$ depth profile, $4=\mathrm{SR}-\mu \mathrm{FTIR}, 5=\mu \mathrm{FTIR}, 6=$ FTIR

On two powder samples transmission FTIR spectroscopy was used. The instrument used was a Shimadzu IR-Affinity 1 spectrophotometer.

In order to determine the thickness of the $\mathrm{CaOx}$ layers, line scans over cross sections of the samples have been performed with SR- $\mu$ XRD at the SOLEIL DIFFABS beamline. The samples were measured in reflection geometry using a collimated X-ray beam $(12.5 \mu \mathrm{m} \times 7.5 \mu \mathrm{m}(H \times V))$ with a primary energy of $19 \mathrm{keV}$. At a reflection angle of $2 \mathrm{de}-$ grees the footprint of the beam on the sample was approx. $360 \mu \mathrm{m} \times 7.5 \mu \mathrm{m}(H \times V)$. Line scans were performed with $5 \mu \mathrm{m}$ step size and an acquisition time of $10 \mathrm{~s} /$ point. XRD images were collected using a Rayonix SX165 detector. On each sample five depth profiles were measured. The images were analyzed by the XRDUA software package developed by the Antwerp X-ray Imaging/Instrumentation Laboratory of the University of Antwerp [18].

\section{Results and discussion}

\subsection{Surface distribution of $\mathrm{CaOx}$}

SEM In Fig. 1 SEM microphotographs of samples treated by different methods are shown. Estimations of the size of the $\mathrm{CaOx}$ crystals present on the surface of the samples were based on the SEM measurements. The smallest crystals (approx. $0.2 \mu \mathrm{m}$ ) were formed using the poultice method with $2 \%$ AmOx solution up to $5 \mathrm{~h}$ (Fig. 1c). Crystal sizes around $0.5 \mu \mathrm{m}$ were found for the brushing method as well as the poultice method with $5 \%$ AmOx for treatments up to $5 \mathrm{~h}$. In general, the immersion method resulted in development of the largest $\mathrm{CaOx}$ crystals $(\leq 1.5 \mu \mathrm{m}$ for treatments up to $5 \mathrm{~h}$ and $\leq 3 \mu \mathrm{m}$ for treatments of 10 and $24 \mathrm{~h}$, Fig. 1b). The poultice method with treatment times of 10 and $24 \mathrm{~h}$ shows development of $\mathrm{CaOx}$ crystals up to $2 \mu \mathrm{m}$. The efficiency of AmOx transport to reaction sites in given treatment time is the highest with immersion treatment, particularly with $5 \%$ AmOx, which is probably the reason for the largest observed crystals.

On all samples small crystals are present around larger ones. On some samples (A5, B5/1, B2/5 and B2/24) large crystals of AmOx were still present (Fig. 1d). Samples A5 and B5/1 also showed development of web-like forms (possible weddellite) (Fig. 1a) [19]. On samples C2/1 and C5/1 no complete surface coverage with $\mathrm{CaOx}$ is observed. For sample A2 it is not conclusive from the SEM photograph whether or not the surface is completely covered with $\mathrm{CaOx}$ crystals. 
Fig. 1 SEM microphotographs of the different samples treated by (a) brushing (A5) —with $\mathrm{CaOx}$ crystal size around $0.5 \mu \mathrm{m}$, and web-like forms of possible weddellite,

(b) immersion (B2/10) — with large whewellite crystal sizes from 2 to $3 \mu \mathrm{m}$ and small crystals from 0.5 to $1 \mu \mathrm{m}$; (c) poultice $(\mathrm{C} 2 / 1)$ - with $\mathrm{CaOx}$ crystal size around $0.2 \mu \mathrm{m}$; (d) immersion (B5/1) — with large AmOx crystals
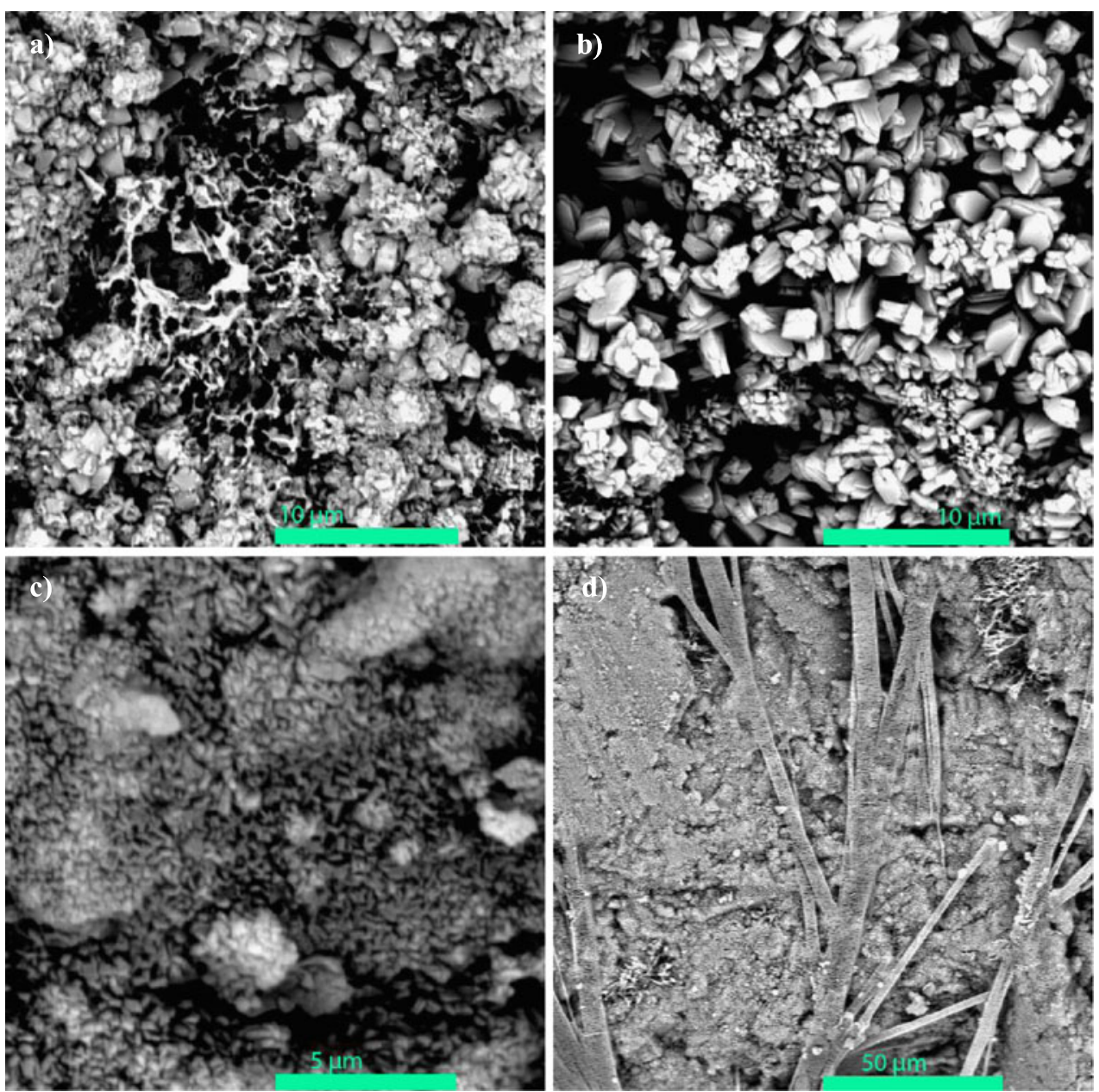

XRD Surface analysis of $\sim 1 \mathrm{~cm}^{2}$ with XRD showed the presence of $\mathrm{CaOx}$ on all samples. Calcium oxalate dihydrate (weddellite), besides calcium oxalate monohydrate (whewellite), is also present on all samples. XRD analysis shows the presence of AmOx on A5, all B5 and C5 samples as well as on B2/10 and B2/24. From these measurements it is clear that AmOx is not present on samples where the treatment was performed with $2 \%$ AmOx solution for the poultice and brushing methods and for the immersion method with short treatment times. The XRD powder pattern of sample A5 is presented in Fig. 2, showing all detected mineral phases.

$(S R-) \mu F T I R \quad$ Statistical analysis of surface maps gained by two different SR- $\mu$ FTIR microscopes identified mostly three different average spectral clusters or phase assemblages. On some samples or different surface sampling areas only two different clusters with significantly different average spectra were identified. The same type of analysis performed by a $\mu$ FTIR microscope with wider analytical window than the two SR- $\mu$ FTIR microscopes used only identified two different clusters with significantly different average spectra or phase assemblages. The third cluster identified by both SR- $\mu$ FTIR microscopes showed strong Reststrahlen bands. Reststrahlen bands present the inverted and distorted calcite and oxalate bands created by measuring the reflected IR light [20, 21]. Identified spectra with two-dimensional area maps for samples A5, B5/24 and C5/24 are presented in Figs. 3, 4, 5. The presented samples were selected to show the comparison of all three different methods using a $5 \%$ AmOx solution for the longest duration. Spectra shown in the figures are averaged spectra produced by CytoSpec software from $\sim 1600$ spectra/sample, so the bands look rounded and wider than on spectra from a single point of analysis. Figures $3 \mathrm{a}$ to $5 \mathrm{a}$ and Figs. $3 \mathrm{~b}$ to $5 \mathrm{~b}$ present results obtained with SR- $\mu$ FTIR microscopes, while Figs. $3 c$ to $5 c$ represent $\mu$ FTIR measurements on the same samples. In some sampling areas (represented by the blue color in Figs. 3-5) average spectra with calcium oxalate absorption bands were recorded. In other areas the average spectra (red color) show medium-intensity bands of calcium oxalate and calcite as well as Reststrahlen bands between 1520 and $1550 \mathrm{~cm}^{-1}$. The third type of average spectra (green color) is characterized by strong Reststrahlen bands between 1520 and 
Fig. 2 XRD powder pattern of sample A5 with marked mineral phases (CA calcite, WH whewellite, WD weddellite, AmOx ammonium oxalate)

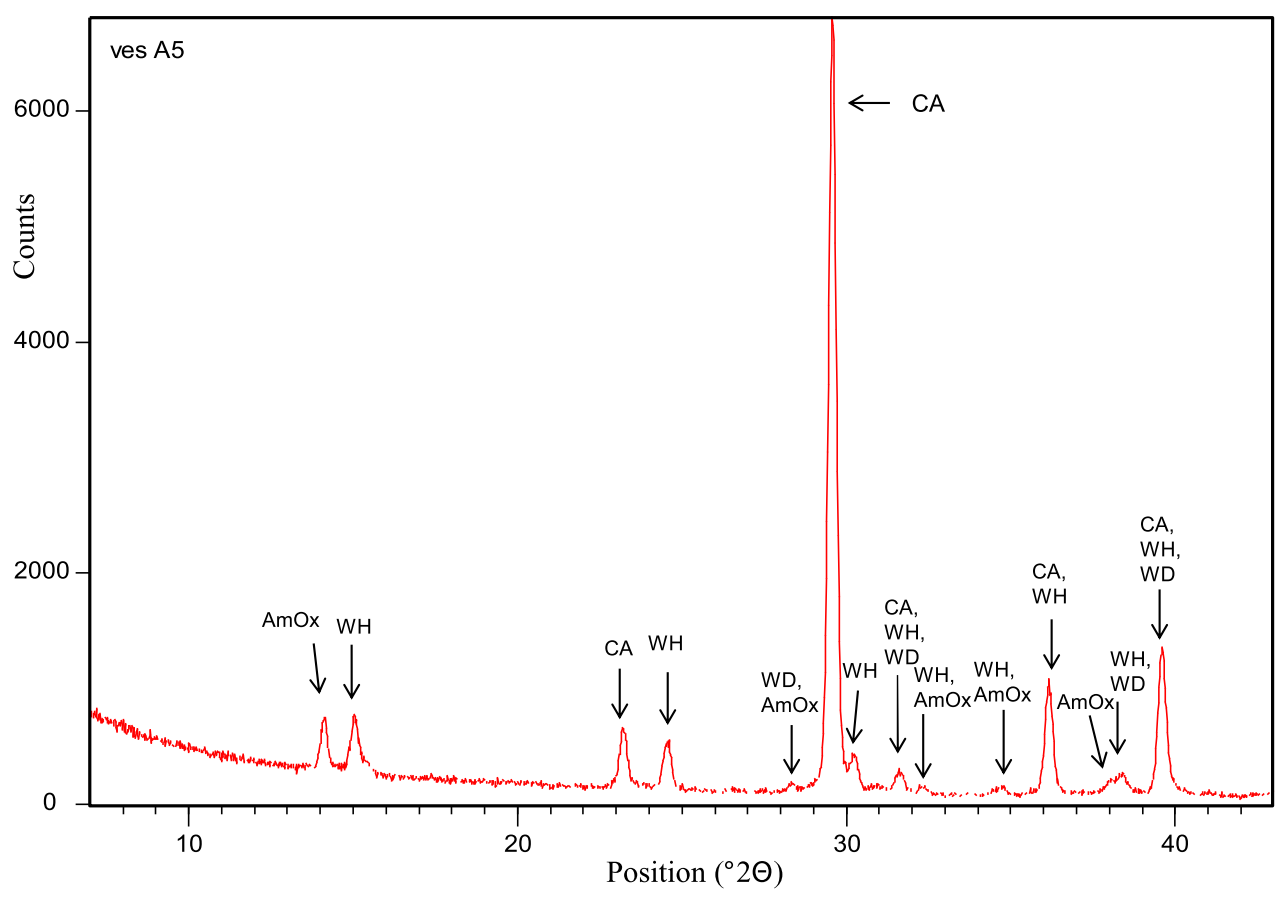

$1550 \mathrm{~cm}^{-1}$ while calcium oxalate and calcite bands have low intensity or are even absent.

If the areas with prominent Reststrahlen bands are considered as areas with mainly calcite and only small amounts of $\mathrm{CaOx}$, we can conclude that the surface of the samples is definitely covered with $\mathrm{CaOx}$ (Figs. 3-5). This fact is in accordance with previous research $[13,21]$, where it has been proven that the oxalate layer is not homogeneous and of equal thickness on the entire treated surface because of the different dissolution of $\mathrm{Ca}^{2+}$ and $\mathrm{CO}_{3}{ }^{2-}$ ions from the calcite surface and different crystal nucleation across the entire surface. Occurrence of Reststrahlen bands is influenced by usage of a smaller analytical window. Samples analyzed with the narrowest analytical window $(10 \mu \mathrm{m} \times 10 \mu \mathrm{m})$ show prominent $R$ bands in most areas. Widening of the analytical window $(20 \mu \mathrm{m} \times 8 \mu \mathrm{m}$ followed by $50 \mu \mathrm{m} \times 50 \mu \mathrm{m})$ shows a decrease of areas with prominent $R$ bands (Figs. 3-5). In general, the results of $\mu$ FTIR spectroscopy showed that most $R$ bands are present in samples treated with the immersion method (B series). As the immersion method should be most effective in the creation of $\mathrm{CaOx}$, this treatment method shows the most intense $R$ bands. This fact can be seen from previous research where longer treatments, which can be considered as more effective, create the most intense $R$ bands [21].

\subsection{Depth profile measurements}

Depth profiles were measured with SR- $\mu$ XRPD in reflection geometry on cross sections of the treated samples. Two criteria for the calcium oxalate layer thickness were defined: the depth after which the amount of whewellite dropped below $50 \%$ of the amount measured on the surface (thickness of protective layer) and the depth after which no more oxalate was observed (penetration depth). These values were determined, using a Pearson VII profile function for single-peak fitting, for the most intense diffraction peak of the phases under investigation, i.e. (020) for weddellite (only penetration depth) and (100) for whewellite (thickness and penetration depth), see Table 2. For the limit of detection it was taken that the peak height of the primary whewellite diffraction line needed to be larger than 10 times the standard deviation of the background.

Not only the oxalate layer thickness, but also the amount of oxalate formed, is important to determine the effectiveness of the different treatments. A brief description of the theoretical background used for this analysis will be given below.

The relationship between the diffracted intensity of one diffraction signal for a given phase $\left(I_{(h k l) \alpha}\right)$ and the weight percentage of this phase $\left(X_{\alpha}\right)$ when a reference sample with known weight fraction $\left(X_{\alpha, \text { ref }}\right)$ is measured under identical conditions $\left(I_{(h k l) \alpha, \text { ref }}\right)$ is given in Eq. (1).

$$
X_{\alpha}=\frac{I_{(h k l) \alpha} \mu_{\beta}}{I_{(h k l) \alpha}\left(\mu_{\beta}-\mu_{\alpha}\right)+I_{(h k l) \alpha, \text { ref }}\left[\mu_{\alpha}+\left(\frac{1-X_{\alpha, \text { ref }}}{X_{\alpha, \text { ref }}}\right) \mu_{\beta}\right]}
$$

This equation is valid for a mixture containing only two phases $(\alpha$ and $\beta$ ). The mass attenuation coefficients of phases $\alpha$ and $\beta$ are given by respectively $\mu_{\alpha}$ and $\mu_{\beta}$. SR$\mu \mathrm{XRD}$ showed the presence of calcite, whewellite and weddellite along the line scans. Weddellite, however, was found 

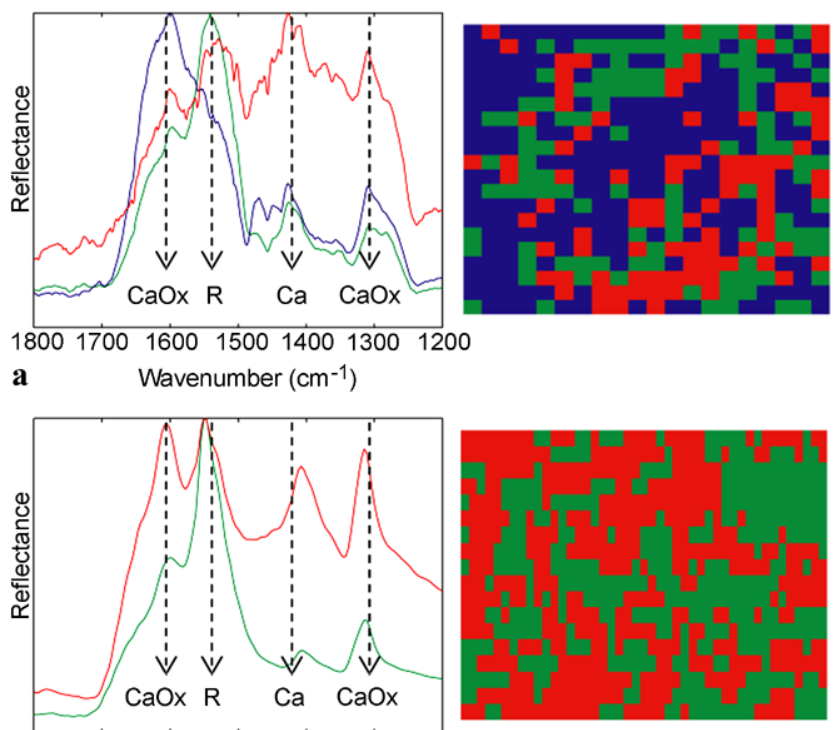

1800170016001500140013001200

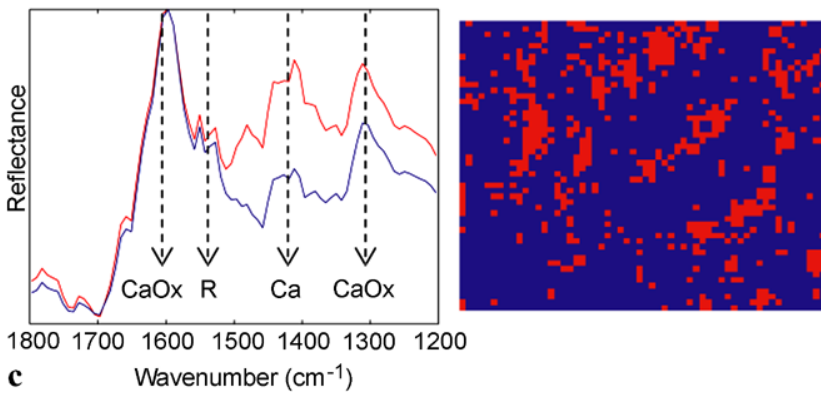

Fig. 3 Surface analysis of sample A5 performed by (a) SR- $\mu$ FTIR microscope on $200 \mu \mathrm{m} \times 200 \mu \mathrm{m}$ area with $10 \mu \mathrm{m} \times 10 \mu \mathrm{m}$ measurement window; (b) SR- $\mu$ FTIR microscope on $360 \mu \mathrm{m} \times 360 \mu \mathrm{m}$ area with $25 \mu \mathrm{m} \times 8 \mu \mathrm{m}$ measurement window; (c) $\mu$ FTIR microscope on $2.9 \mathrm{~mm} \times 2.6 \mathrm{~mm}$ area. Average IR spectra (on left) and area where such spectra were recorded (on right) are shown (blue- $\mathrm{CaOx}$; red- $-\mathrm{CaOx}$, calcite and Reststrahlen bands; green-Reststrahlen bands)

only on the surface of the samples and in some cases with low intensity below the surface, with the exception of samples treated by brushing. The presence of weddellite was therefore neglected during this procedure.

As no reference sample was measured, the weight fraction of whewellite in the different measurements could not be determined. If however the measurement which showed the highest intensity for whewellite (100) is taken as reference and two extreme cases are assumed where the weight fraction of whewellite in the reference measurement is either $X_{\alpha, \text { ref }}=1 \mathrm{wt} . \%$ or $X_{\alpha, \text { ref }}=99 \mathrm{wt} . \%$, a comparison between the different samples can be made. The amount of whewellite formed in the samples $\left(m_{\alpha}\right)$ is dependent on three factors, as seen in Eq. (2): the weight fraction of whewellite $\left(X_{\alpha}\right)$ and the density of the sample $\left(\rho_{s}\right)$ in each point $i$ along the line scan and a volume which is considered the same for all samples and for all points in the line scan.
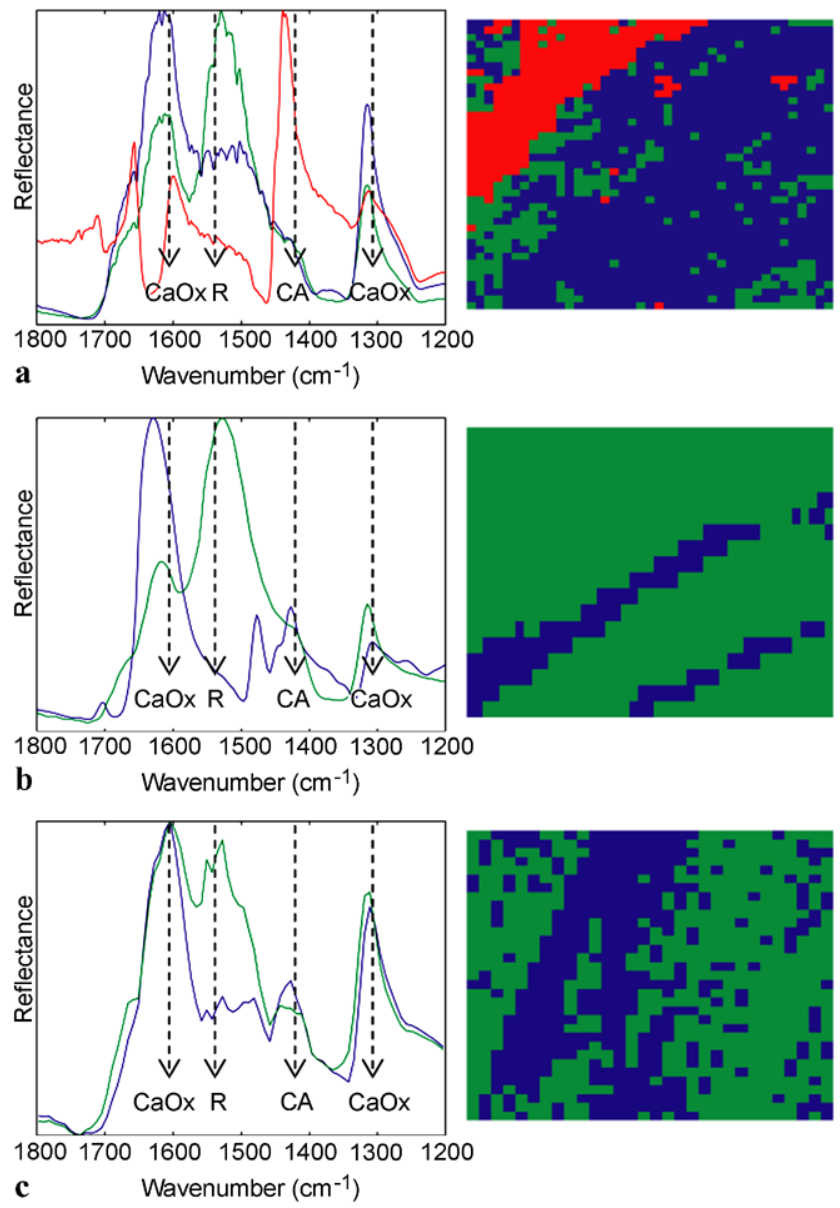

Fig. 4 Surface analysis of sample B5/24 performed by (a) SR- $\mu$ FTIR microscope on $400 \mu \mathrm{m} \times 400 \mu \mathrm{m}$ area with $10 \mu \mathrm{m} \times 10 \mu \mathrm{m}$ measurement window; (b) SR- $\mu$ FTIR microscope on $360 \mu \mathrm{m} \times 360 \mu \mathrm{m}$ area with $25 \mu \mathrm{m} \times 8 \mu \mathrm{m}$ measurement window; (c) $\mu \mathrm{FTIR}$ microscope on $1.65 \mathrm{~mm} \times 1.5 \mathrm{~mm}$ area. Average IR spectra (on left) and area where such spectra were recorded (on right) are shown (blue- $\mathrm{CaOx}$; red- $\mathrm{CaOx}$, calcite and Reststrahlen bands; green-Reststrahlen bands)

Index $i$ runs over the number of points measured before the penetration depth was reached $(n)$.

$m_{\alpha}=V \sum_{i}^{n} X_{\alpha, i} \rho_{s, i}$

All amounts given in Table 2 are relative to sample B5/10 (Table 2, Figs. 6 and 7) in order to eliminate the volume factor given in Eq. (2). The differences in the relative amounts obtained with $X_{\alpha, \text { ref }}=1 \mathrm{wt} . \%$ and $X_{\alpha, \text { ref }}=99 \mathrm{wt} . \%$ are smaller than the errors obtained due to heterogeneity of the samples.

Results (Table 2) showed that for all the samples the whewellite protective layer thickness does not exceed $40 \mu \mathrm{m}$. No clear relationship between the thickness of the layer and the treatment time was observed. The penetration depth of the whewellite generally becomes larger as the treatment time increases. 


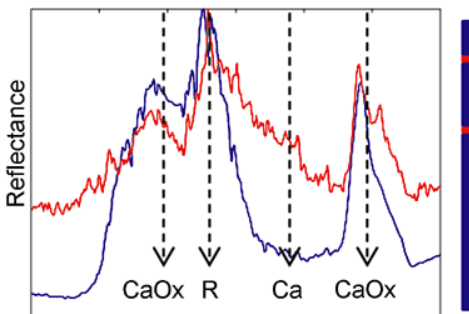

1800170016001500140013001200

a

Wavenumber $\left(\mathrm{cm}^{-1}\right)$
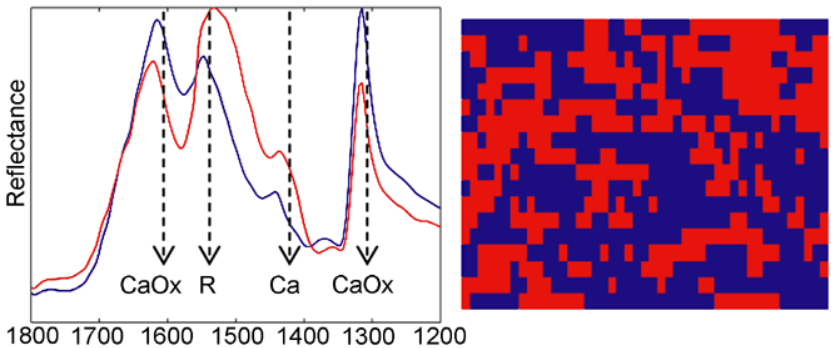

$\begin{array}{llll}18001700160015001400130(1) \\ \text { b } & \text { Wavenumber }\left(\mathrm{cm}^{-1}\right)\end{array}$

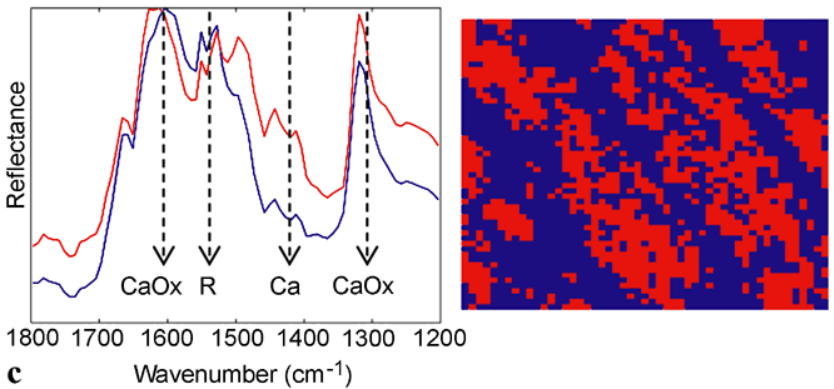

Fig. 5 Surface analysis of sample C5/24 performed by (a) SR- $\mu$ FTIR microscope on $400 \mu \mathrm{m} \times 400 \mu \mathrm{m}$ area with $10 \mu \mathrm{m} \times 10 \mu \mathrm{m}$ measurement window; (b) SR- $\mu$ FTIR microscope on $360 \mu \mathrm{m} \times 360 \mu \mathrm{m}$ area with $25 \mu \mathrm{m} \times 8 \mu \mathrm{m}$ measurement window; (c) $\mu$ FTIR microscope on $2.55 \mathrm{~mm} \times 2.75 \mathrm{~mm}$ area. Average IR spectra (on left) and area where such spectra were recorded (on right) are shown (blue- $\mathrm{CaOx}$; red-CaOx, calcite and Reststrahlen bands)

All treatments using a solution with higher AmOx concentration result in an increase in the thickness and the penetration depth of the oxalate layer compared with treatments with lower AmOx concentration. Even though not all samples show a significant increase in layer thickness as AmOx concentration increases, the overall correlation is evident from the data presented. The largest penetration depths were found for samples immersed in $5 \%$ AmOx solution (B5).

From the results shown in Table 2 and Fig. 6 it is evident that the relative amount of whewellite in the samples is dependent on the treatment time, ammonium oxalate concentration and method of application. The increase in AmOx concentration has a strong effect on treatments up to $5 \mathrm{~h}$, showing a significant increase in relative amounts of whewellite formed. Treatments longer than $5 \mathrm{~h}$ show approximately the same relative amount of whewellite for both 2 and $5 \%$ solutions of AmOx. Poultice treatments with a treatment time longer than $10 \mathrm{~h}$ show a lower rela- tive amount of whewellite when compared to the immersion treatment. However, the penetration depth for this method of treatment is much smaller, which causes the whewellite that is present to be situated in a smaller area close to the surface. The amount of whewellite formed after one hour of brushing treatment is comparable to both the immersion and poultice treatments with treatment times of $10 \mathrm{~h}$ or longer, with the exception of sample B5/10. From Table 2, it is obvious that immersion treatment in general creates the highest relative amounts of whewellite, followed by brushing and poultice treatments. The relative amount of whewellite in sample C5/1 seems inconsistent with the other samples. This is probably due to uneven structural properties of the stone.

As illustrated in Fig. 7, the brushing treatment, with a treatment time of one hour, creates a $\mathrm{CaOx}$ layer similar to (or better than) a $10 \mathrm{~h}$ or more poultice treatment using a 2 or $5 \%$ AmOx solution. The results could be explained as follows:

General observation: in all three types of treatment the reaction on the surface and the diffusion within the stone sample must comply with the same mechanisms and limitations. Therefore, the differences between the treatments have to be interpreted in terms of transport of the reactant (AmOx) from the bulk of the solution to the outer boundary of the stone sample.

Poultice treatment $(C)$ : the concentration of the $\mathrm{AmOx}$ solution at the phase border drops rapidly because the reactant is only renewed from the poultice by molecular diffusion (slow process).

Immersion treatment $(B)$ :

- the $2 \%$ AmOx solution might not be concentrated enough to assure effective transport of the reactant by natural convection (stirring); therefore, reactant is only transferred to the stone surface by molecular diffusion;

- the $5 \%$ solution of AmOx might be concentrated enough to make natural convection an effective transport mechanism. This gives rise to the best in-depth development of whewellite.

Brushing treatment $(A)$ : the concentration of the ammonium oxalate solution at the phase border is constantly renewed. The average concentration on the sample surface is a function of the brushing rate and the frequency and duration of the break intervals. The surface reactant concentration is diminished by diffusion of reactant in the pores of the sample and the surface reaction resulting in the formation of calcium oxalate. On the other hand, the concentration is increased by the permanent evaporation of the solvent (water) from the outer surface of the sample.

To verify this theory, Veselje stone was crushed to grains with a size between 0.125 and $0.250 \mathrm{~mm}$ and treated by immersion in $2 \%$ AmOx for one hour with and without stirring. The treated materials were measured with FTIR, which 


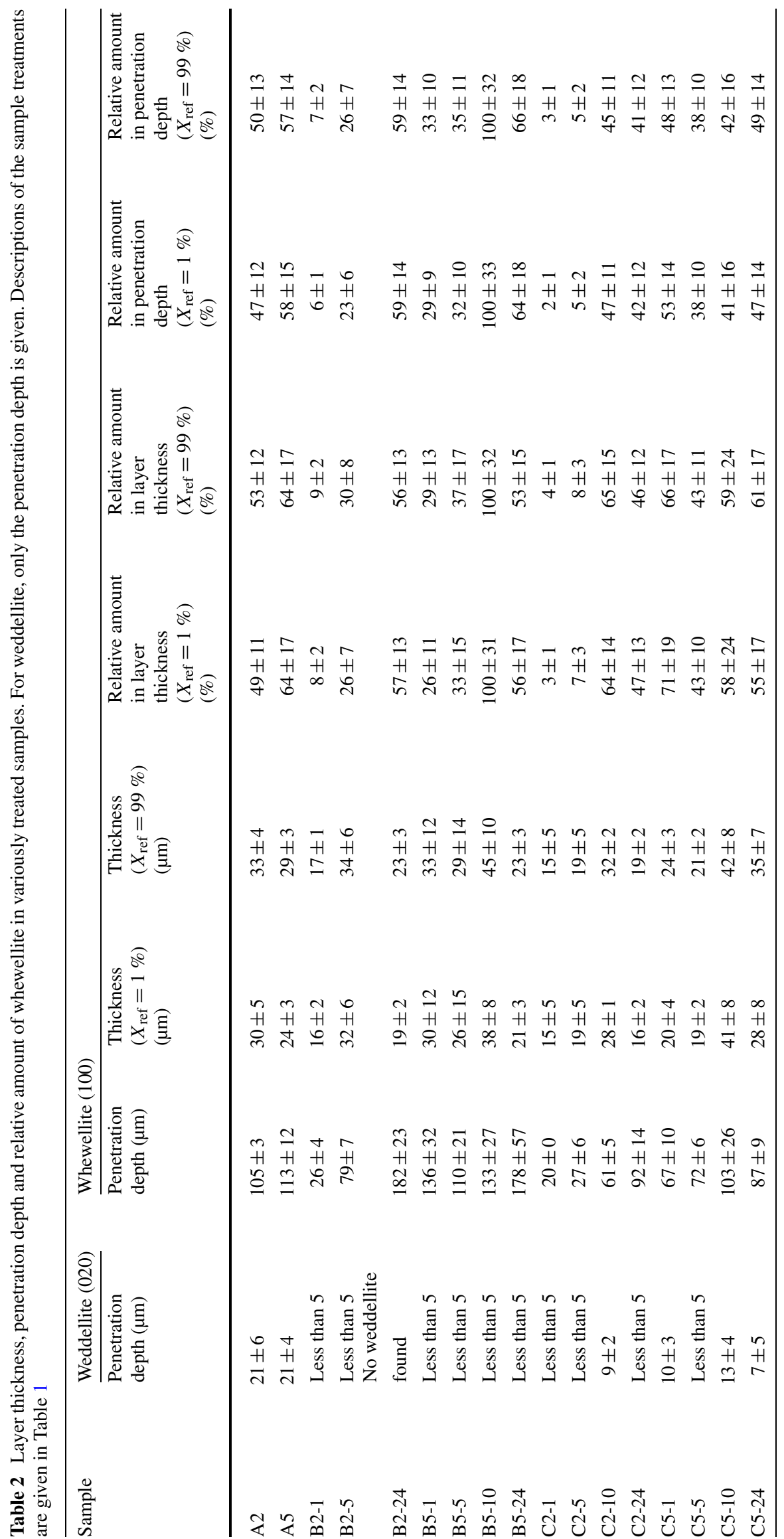


Fig. 6 Relative amount of whewellite present in the protective layer

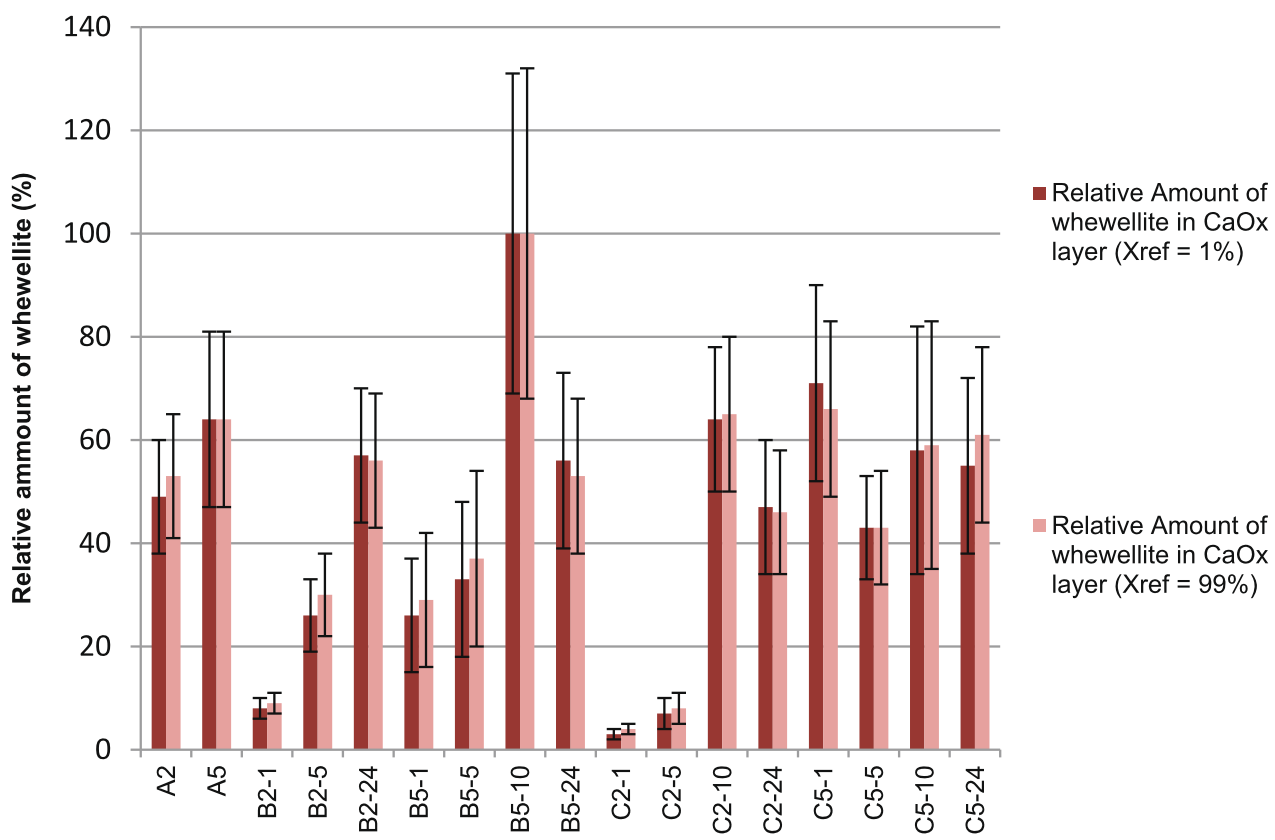

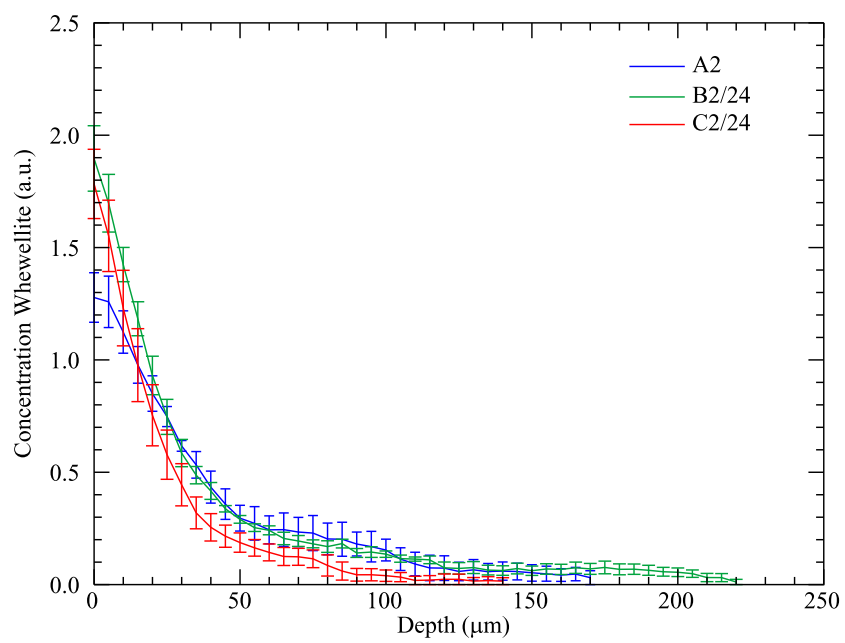

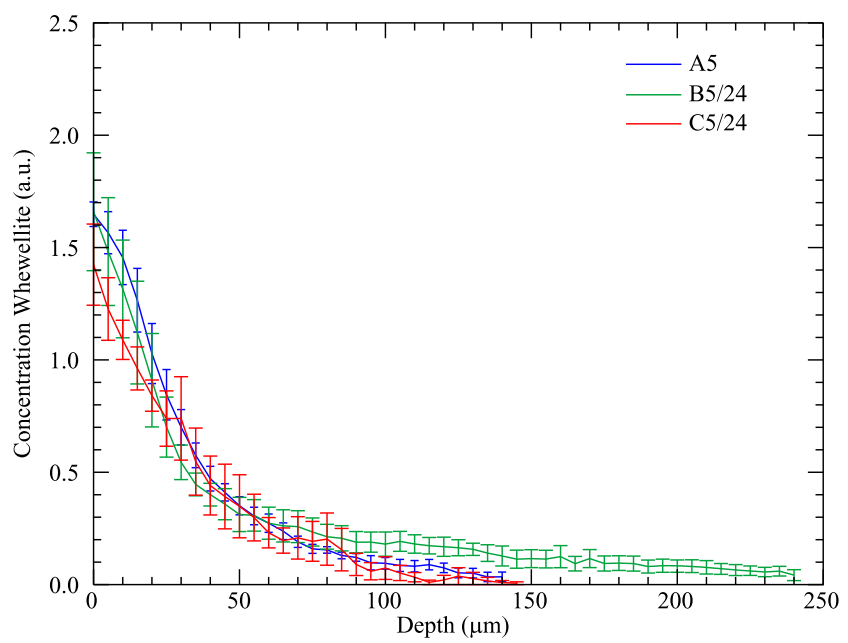

Fig. 7 SR- $\mu$ XRPD depth profiles showing the concentration of whewellite calculated using $X_{\alpha, \text { ref }}=99$ wt. $\%$ (in arbitrary units) for the brushing, immersion and poultice treatments with $2 \%$ (left) and $5 \%$ (right) AmOx. The profiles are the averages of four or five line scans for each sample

showed higher intensities for whewellite when the solution was stirred (Fig. 8).

\section{Conclusions}

Surface measurements at macro scale (XRD measurements of $\sim 1 \mathrm{~cm}^{2}$ ) showed the presence of $\mathrm{CaOx}$ on all samples. Even though ordinary laboratory FTIR microscopy with sampling size of $50 \mu \mathrm{m} \times 50 \mu \mathrm{m}$ showed a full coverage of $\mathrm{CaOx}$ on all samples at the macro scale, SR-based $\mu$ FTIR microscopy showed that the surface of the stone is not evenly covered with calcium oxalate at the microscopic level. This is consistent with observations of the treated sur- face with SEM, which shows that $\mathrm{CaOx}$ is growing in clusters, resulting in an uneven surface coverage. SEM investigations revealed that longer treatment times create larger oxalate crystals. In the IR spectra, Reststrahlen bands between 1520 and $1550 \mathrm{~cm}^{-1}$ are found heterogeneously distributed along the samples. Since they represent inverted and distorted calcite and $\mathrm{CaOx}$ bands, they can also be considered as proof for an unevenly covered surface. All stone samples have irregular structural properties, which makes quantitative analysis of the IR spectral data unreliable. Therefore, we used large data sets to minimize the contribution of random effects.

Depth measurements: The samples immersed in AmOx solution (series ' $\mathrm{B}$ ') show an increase in the observed $\mathrm{CaOx}$ 
Fig. 8 Influence of stirring the immersion solution on the formation of $\mathrm{CaOx}$ for crushed stone samples treated with $2 \%$ solution of AmOx for one hour with (in red) and without stirring (in blue)

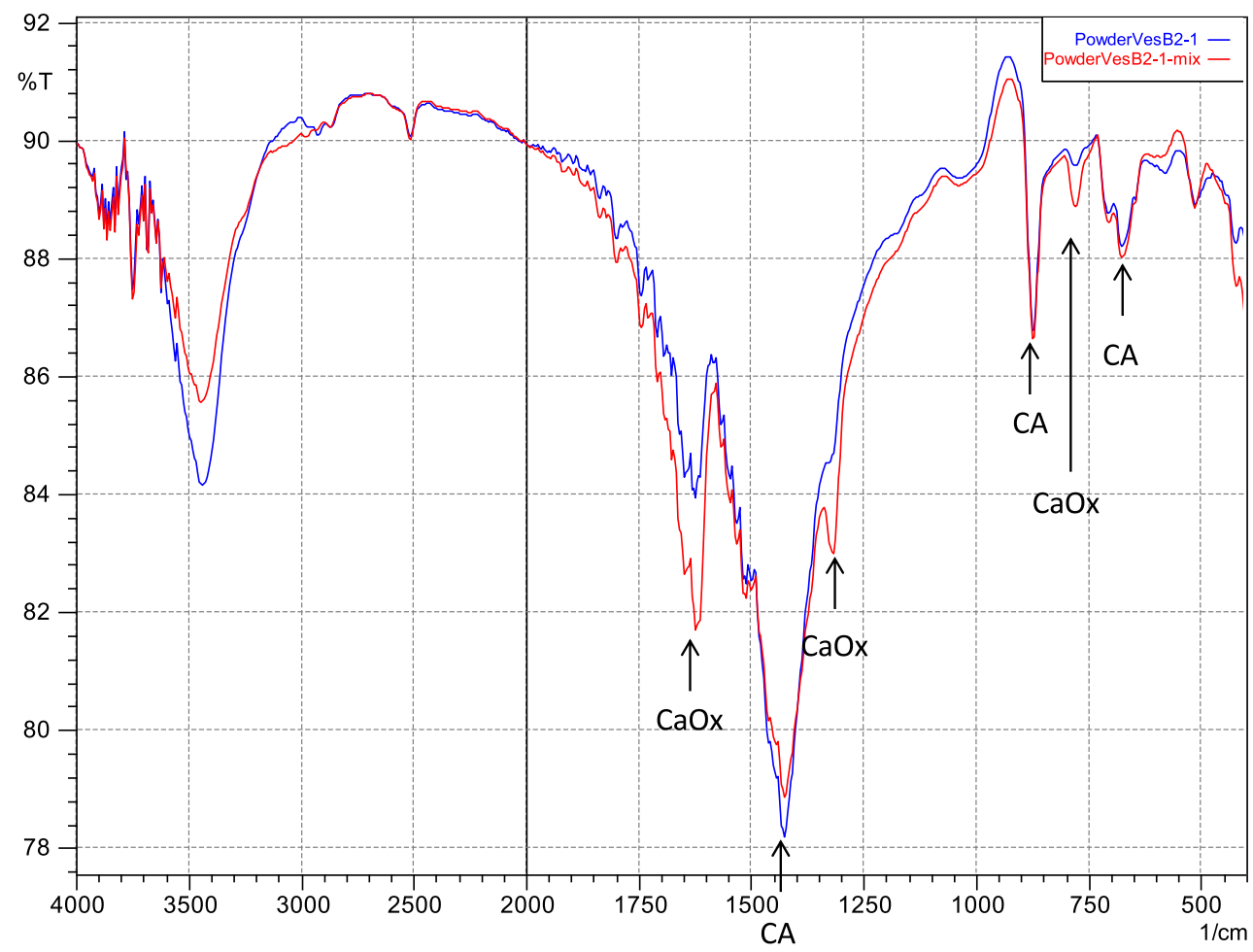

penetration depth with longer immersion times and a higher ammonium oxalate concentration used. The best in-depth development of calcium oxalate monohydrate (whewellite) with the highest relative amount of whewellite is found in these samples. Minor discrepancies observed for sample $\mathrm{B} 5 / 5$ are most probably due to uneven structural properties of the stone sample. The samples treated with a cellulose poultice (series ' $C$ ') show results which are consistent with the treatment time. Samples treated by the poultice method with $5 \%$ AmOx solution show the development of higher relative amounts of whewellite in shorter treatment times (until $10 \mathrm{~h}$ ). Relative amounts of whewellite for treatments longer than $10 \mathrm{~h}$ seem to be independent of the $\mathrm{AmOx}$ concentration used. Minor discrepancies for sample C5/1 are most probably caused by the same factors as for sample B5/5.

The samples treated by the brushing treatment showed similar results for the amount of whewellite formed when compared with both the poultice and immersion treatments using a treatment time of $10 \mathrm{~h}$ or longer. Besides whewellite (calcium oxalate monohydrate), weddellite (calcium oxalate dihydrate) was found to be clearly present on samples treated with the brushing treatment.

It can be concluded that for all the samples the surface is unevenly covered with $\mathrm{CaOx}$. Inconsistencies of the estimated thickness and penetration depth, based on treatment time, could be due to structural properties of the studied stone type. The $\mathrm{CaOx}$ layer thickness ranges from 30 to $40 \mu \mathrm{m}$ for the brushing treatment and for immersion and poultice treatments of $10 \mathrm{~h}$ or longer. Concentrated solutions of AmOx result in a larger layer thickness and bigger crystals in a shorter time. The concentration of the AmOx solution used does not seem to influence the relative amount of whewellite formed when treatment times of $10 \mathrm{~h}$ or longer are applied. The immersion treatment with $5 \%$ AmOx gives rise to the biggest crystals and the thickest $\mathrm{CaOx}$ layer.

As final conclusion, it can be said that for large surfaces the brushing treatment presented in this work can be considered as an efficient method for the creation of a protective $\mathrm{CaOx}$ layer. This layer will be similar to that obtained by a 10 to $15 \mathrm{~h}$ poultice treatment, which is proved to form sufficient covering of the stone surface [21]. A possible problem on some brighter marble and types of limestone could be that the brushing treatment creates small crystals which can result in an increase in the diffuse reflectance of light [21]. This could make the stones look a bit more greyish than before treatment. This was however not the case with the Veselje stone investigated in this study.

Acknowledgements We would like to thank Dr. Paul Dumas from the SMIS beamline at the 'SOLEIL' synchrotron in Saint-Aubin (France) for his help in the statistical analysis of the IR maps. Also, we would like to thank Dr. Cristian Mocuta from the DIFFABS beamline at the 'SOLEIL' synchrotron for his great help during the XRD depth measurements. We also appreciate the help of Dr. Philippe Lerch from the IR beamline at the 'Swiss Light Source synchrotron, Paul Scherrer Institute' in Villigen (Switzerland) during the surface IR measurements.

This research was supported by the Interuniversity Attraction Poles Programme-Belgian Science Policy (IUAP VI/16). The text also presents results of GOA 'XANES meets ELNES' (Research Fund, 
University of Antwerp, Belgium) and from FWO (Brussels, Belgium) project nos. G.0704.08 and G.01769.09.

The research leading to these results has received financial support by the Access to Research Infrastructures activity in the 7th Framework Programme of the EU (CHARISMA Grant Agreement No. 228330).

\section{References}

1. E. Hansen, E. Doehne, J. Fidler, J. Larson, B. Martin, M. Matteini, C. Rodríguez-Navarro, E.S. Pardo, C. Price, A. De Tagle, J.M. Teutonico, N. Weiss, Rev. Conserv. 4, 13 (2003)

2. V. Fassina, Proceedings, Le Pellicole Ad Ossalati Origine e Significato nella Conservazione delle Opere D'Arte (Centro 'Gino Bozza', Milano, 1989), p. 381

3. M. Realini, L. Toniolo, International Symposium II: The Oxalate Films in the Conservation of Works of Art (Editeam, Castello D'Argile, 1996), p. 539

4. K. Kouzeli, N. Beloyannis, C. Tolias, Y. Dogani, in Le Pellicole Ad Ossalati Origine e Significato nella Conservazione delle Opere D’Arte, ed. by V. Fassina (Centro 'Gino Bozza', Milano, 1989), pp. 327-336

5. D. Camuffo, Sci. Total Environ. 128, 205 (1993)

6. M. Matteini, Conserv. Sci. Cult. Herit. 8, 13 (2008)

7. D. Pinna, B. Salvadori, S. Porcinai, Constr. Build. Mater. 25, 2723 (2011)

8. M. Matteini, A. Moles, in Le Pitture Murali: Techniche, Problemi, Conservazione, ed. by A. Moles (Centro Di, Florence, 1990), pp. 297-302

9. M. Matteini, A. Moles, S. Giovannoni, in Proceedings of the 3rd International Symposium: The Conservation of Monuments in the
Mediterranean Basin: Stone and Monuments: Methodologies for the Analyses of Weathering and Conservation, ed. by V. Fassina, H. Ott, F. Zezza (Soprintendenza ai Beni Artistici e Storici di Venizia, Venice, 1994), pp. 155-162

10. M. Matteini, A. Moles, G. Lanterna, M.R. Nepoti, in International Symposium II: The Oxalate Films in the Conservation of Works of Art, ed. by M. Realini, L. Toniolo (Editeam, Castellio D'Argile, 1996), pp. 425-440

11. M. Ambrosi, P. Baglioni, P.R. David, L. Dei, R. Giorgi, C. Lalli, A. Mairani, M. Matteini, M. Rizzi, G. Schonhaut, G. Lanterna, in Proceedings, Science and Technology for the Safeguard of Cultural Heritage in the Mediterranean Basin, ed. by A. Guarino (Elsevier, Paris, 2000), pp. 855-858

12. A. Mairani, M. Matteini, M. Rizzi, OPD, Restauro 12, 146 (2000)

13. B. Doherty, M. Pamplona, M. Matteini, A. Sgamellotti, B. Brunetti, J. Cult. Herit. 8(2), 186 (2007)

14. http://whc.unesco.org/en/list/97

15. X'Pert HighScore Plus (PANalytical B.V., Almelo, 2004)

16. ICDD-International Centre for Diffraction Data, in Powder Diffraction File PDF-2 (ICDD, Newtown Square, PA, 2004)

17. http://www.cytospec.com; CytoSpec ver. 1.2, CytoSpec, Inc., USA (2005)

18. W. De Nolf, K. Janssens, Surf. Interface Anal. 42(5), 411 (2010) Spec. Issue: Surf. Sci. Appl. Forens. Anal.

19. A.M. Cody, R.D. Cody, J. Cryst. Growth 151, 369 (1995)

20. C. Ricci, C. Miliani, B.G. Brunetti, A. Sgamellotti, Talanta 69, 1221 (2006)

21. B. Doherty, M. Pamplona, R. Selvaggi, C. Milliani, M. Matteini, A. Sgamellotti, B. Brunetti, Appl. Surf. Sci. 253(10), 4477 (2007) 